\title{
2.I Introduction
}

The term 'complex predicate' has a wide usage, including, for example, serial verb constructions, light verb constructions, and particle + verb constructions, among others. An examination of the data provided by analysts in their discussions of complex predicates shows that monoclausality is the critical factor in determining whether a construction involves a complex predicate or not. Complex predicates are monoclausal structures involving two or more predicating morphemes. Butt (this volume) is explicit on this point.

[T] he term complex predicate is used to designate a construction that involves two or more predicational elements (such as nouns, verbs, and adjectives). whicb predicate as a single element, i.e. their arguments map onto a monoclausal syntactic structure.

We show that monoclausality as a criterion does not determine a unitary set of predicate structures. Rather, we show that there are two quite distinct ways of combining predicate information within monoclausal structures. We call one method 'merger' because the predicate information from the contributing constituents merges where they have common conceptual structure. This method produces predicate structures whose range classes with the range of predicate structures found in monomorphemic predicates. We propose that there are constraints on the conceptual structure of monomorphemic predicates which also apply to merger constructions. We discuss the constraints on monomorphemic predicates in Section 2.4.

We call the other method 'coindexation' because relations among the contributing predicates are constrained only by a requirement that some of their arguments must be coindexed. This method produces multi-predicate

* We would sincerely like to acknowledge the important contribution of the following scholars to the ideas developed in this paper, even though they would not necessarily agree with our arguments: Mengistu Amberber, Jahn Beavers, Bill Foley, Clifr Goddard, Andrew Koontz-Garboden, Beth Levin, Rachel Nordlinger, Nick Reid, Eva Schultze-Berndt, and audiences at Manchester, USC, Nijmegen, AIS 2006 in Brisbane, and LSA 2007 in Ansheim. 
structures whose range classes with multi-clausal structures. The range may overlap to some degree with that of monomorphemic and merger predicates, but always extends to conceptual structures which cannot be expressed by monomorphemic and merger predicates. Given that coindexation structures are multi-predicational, they are not subject to the constraints on the ceptual structures of monomorphemic and merger. predicates.

The distinction we draw between two classes of conceptual structure associated with monoclausal structures is independent of morphological or syntactic oppositions. As we will see, there are some common associations between each of the classes of conceptual structure and particular morphosyntactic structures. However, there are no bi-directional one-to-one correspondences between a particular conceptual structure class and a particular morphosyntactic structure.

We may illustrate the opposition in conceptual structure classes by comparing two apparently similar morphosyntactic constructions, whose predicate interpretations are very different. The first construction is a coindexation construction, in this case a serial verb construction. These are well known in the literature on complex predicates. The following example from Barai (Papua New Guinea) is typical.

(I) fu burede ije
he bread

'He cut the bread with the knife.' (Barai - Foley and Olson 1985: 44)

In Barai, abe 'take' is a 'light' verb which adds the function 'with $x$ [instrument]' to the clause. This is a very common pattern with serial verb constructions (Aikhenvald 2006).

We illustrate merger constructions with a less well-known class of complex predicates: the class of 'coverb' constructions. Consider the following example from the Australian language Marra (Heath 1981).

$$
\begin{aligned}
& \text { rang =ng-anyi } \\
& \text { hit=1 } \quad \text { SG.S/35G.O-TAKE.PC } \\
& \text { 'I hit a rock.' (Not: 'I hit it with a rock.') }
\end{aligned}
$$

The coverb construction involves two different kinds of verbal words - a coverb, in this case rang 'hit', and an inflected finite verb, here nganyi which means ' $I$. was taking it' when used as an independent verb. Coverbs constitute a basic word class. They are non-derived, inherently predicational, and inherently non-finite. That is, they do not inflect for tense, mood or agreement, but may inflect for aspect.

In the coverb construction, the coverb generally conveys the main lexical meaning in the complex predicate. The finite verb usually, but not necessarily, functions as a light verb. It conveys tense, aspect, mood, and agreement, and some very general predicate information ('generic' in the terms 
of Schultze-Berndt 2000: 83). As we will see (section 2.5), it also determines argument structure. ${ }^{3}$

Both (I) and (2) involve two inherently predicational constituents, and in both the 'take' verb is a light verb. Yet their interpretations are very different. In ( $\mathrm{I}$ ), the 'take' verb adds an instrumențal argument. By contrast, in (2), it does not add an instrumental argument. Rather, it provides the necessary tense, aspect, and agreement information that the coverb cannot itself provide.

\subsection{Merger constructions}

Among languages which have complex predicate structures, there are some languages which have only merger structures. ${ }^{2}$ This includes many languages of northern Australia. We illustrate the range of conceptual structures characteristic of merger constructions with data from Marra. In Marra, the class of verbs is a small closed class with 38 members (Heath 1981: 230-46). The coverb class is an open class. The great majority of 'verbal' predicates are expressed through the coverb construction. Nearly all the languages of north-central and north-western Australia have this same pattern of organisation for verbal predicate meanings.

In all languages with the coverb construction, a sizeable number of coverb lexemes can co-occur with two or more different finite verbs. In the great majority of cases, the alternation between finite verbs has a semantically predictable effect on the meaning of the complex predicate. In every language with the coverb construction, the construction codes alternations in transitivity. Monovalent coverbs, such as dirra 'be tied up' and birli 'go in' may be combined with both transitive and intransitive finite verbs.

(3) dirra=nga-jurliyi

be.tied.up=ISG.S-BE.PR

'I am tied up.'

(4) birli=gu-lini

go.in $=3$ SG.S-GO.PC

'He went in.'

(5) dirra=nan-bili-ju

be.tied.up=ISG.O-3PL.S-DO.FUT

'They are going to tie me up.'

- Coverb constructions are found in many languages of northern Australia, including Warlpiri (where they are commonly called 'preverb' constructions), as well as many languages of the Ethio-Semitic family (e.g. Amharic: Amberber: this volumc), Kurdish, Persian (Megerdoomian 2001, Folli et al. 2005), and many languages of Papua New Guinea and South America.

2 It is unclear whether there are languages which permit only coindexation. The well-known serialising languages of West Africa such as Twi may be of this type, but we lack sufficient information to be certain. 
(6)

$$
\begin{aligned}
& \text { birli=nga- } \oslash \text {-ganji } \\
& \text { go.in=ISG.S-35G.O-TAKE.PP } \\
& \text { 'I put it in(side).' }
\end{aligned}
$$

As illustrated, the finite verb determines the argument structure of the overall merger construction.

Significantly, these alternations apply productively to loaned coverbs in all the Australian languages we have examined. In Marra, for example, loaned verbs take a range of light verbs. In general, the light verb appears to be selected on an analogical basis: a loaned coverb takes the same light verb as native coverbs with related meanings. Hence, we assume that the verb bendijimap 'bandage' (tr.), borrowed from Kriol (an English-lexifier creole spoken across northern Australia) takes the light verb jujunyi 'do' (7) because coverbs with a similar meaning, such as dirra 'be tied up' do also (5). ${ }^{3}$

(7) bendijimap $=$ nan-bili-ju

bandage $=1$ SG.O-3PL.S-DO.FUT

'They are going to bandage me up.'

We should not be particularly surprised that a light verb such as jujunyi 'do', with Ios of the total of 728 coverbs listed in the dictionary (Heath r98I), can derive new loans. What is most striking about Marra is that even light verbs with a small class of coverbs can derive new loans. For instance, the light verb janyi 'tell' takes just 49 attested coverbs, yet it too can derive new loans (8), again apparently by analogy with coverbs of related meaning (9).

$$
\begin{aligned}
& \text { ringimap=nan-bili-yi } \\
& \text { ring=ISG.O-3PL.S-TELL.PP } \\
& \text { 'They rang me.' }
\end{aligned}
$$

(9) gaw =nan-bili-yi

$$
\text { call }=\text { I SG.O-3PL.S-TELL.PP }
$$

'They called me.'

Apart from transitivity alternations, manner specifications are another common function of coverbs, as illustrated in (10)-(13) (Heath 198I). ${ }^{4}$

3 Except where orherwise indicated, Marra examples are taken from the first author's feldnotes, 2005. Marra finite verbs have complex, largely irregular inflectional paradigms for tense/aspect/mood (see Heath 1981 ). Finite verbs are cited in their citation form in Heath (1981), which is the Past Continuous Durative form, for most ver.bs. We use the standard orthography now in use for teaching and documentation purposes by Marra speakers, hence the representational differences from Heath (198I).

- A reviewer asks whether ( 10 ) and (II) include the meaning of 'bite' as well as the meaning of the coverb. We assume that, in keeping with the behaviour of this construction in Marra 
(10) jag $=$ nga- $\varnothing$-bayngarli

chew.briefly= ISG.S-3SG.O-BITE.PC

'I chewed it briefly.'

(II) buny $=$ nga- $\varnothing$-bayngarli :-

suck= I SG.S-3SG.O-BITE.PC

'I was sucking on something.'

(I2) gil=nga-lini

crawl= $r S G . S-G O . P C$

'I was crawling along.'

(13) jarlarla =nga-lini

walk. around = ISG.S-GO.PC

'I went for a walk.'

In some languages, such as Marra, coverbs never appear independently. They are always in a dependency relationship with some finite verb. Indeed, speakers do not recognise some coverbs independently of the inflected finite verb. If the linguist pronounces these coverbs independently, speakers will insist that the finite verb must be pronounced also. In other cases, speakers will recognise the coverb and even give a sense for it.

In orher languages, such as Jaminjung (Schultze-Berndt 2000) and Wagiman (Wilson 1999), coverbs have relatively greater independence. They can appear immediately after the finite verb (approximately to percent of clauses). They appear as independent words, and occur in imperatives and in non-initial clauses without an accompanying finite verb. However, in no Australian languages do coverbs as a class have the full range of possibilities for inflection and independence that finite verbs have. Clearly, coverbs form a separate part-of-speech class in these languages.

\subsection{Coindexation constructions}

One of the best-known classes of coindexation constructions is serial verb constructions. Serial verb constructions are found as an areal feature of many West African languages such as Twi (Lord 1993), East Asian languages such as Cantonese (Matthews and Yip 1994), Oceanic languages such as Ambae

and other languages, they do not, but we have not explicitly tested these examples with speakers. The translations are those given by Heath in the dictionary section of his grammar of Marra (198I). In general, as we discuss in section 2.5, the meanings of coverb complexes merge the meanings of the constituent predicates, such that more specific meanings (such as 'chew briefly') tend to override more general meanings (such as 'bite'); moreover, many finite verbs can be regarded as realising a semantically 'bleached' meaning in coverb constructions, compared to their meaning as independent verbs. We assume this is the case with these examples. 
(Crowley, 2002), Papuan languages (Foley 1986), and also many Caribbean creoles (Sebba 1987).

As with the term 'complex predicate', the term 'serial verb' has been applied to a wide variety of constructions with many kinds of semantic structures involved. Here we focus on some representative serial veŗb structures, such as benefactive marking with 'give', comitative marking and object marking with 'take', and complementisers with 'say'. None of these can be conveyed by merger constructions.

The following examples are from Twi (Lord 1993: 32; citing Christaller I875: 139 and I88I: 463 , respectively). In (I4) and (I5) we see the 'give' verb being used to introduce a non-subcategorised dative argument into a monoclausal structure.

(14) agejkwã no wú mãã yệ
Saviour the die GIVE us
'The Saviour died for us.'
(15) dan mu ho n-sõ m-mã
house in there NEG-belarge NEG-Give them
'The house is not large enough for all of them.'

In (I6) and (17), we find the 'take' verb de being used to introduce a nonsubcategorised argument - in this case an instrumental - into a monoclausal structure.

(16) o-de n'ensa beñkum o-didi
he-TAKE his-hand left
'He eats with his left hand.'
(I7) o-de eat
he-TAKE hook he-cut branch
'He cut off a branch with a hook.'

This function - the introduction of non-subcategorised arguments into monoclausal structures - is a prominent feature of serial verb constructions in West African languages and Caribbean creoles (Lord r993), as well as Southeast Asian languages (e.g. Cantonese: Matthews and Yip 1994). This function is not universally a prominent characteristic of serial verb constuctions - it is not typical of serial constructions in Oceanic languages (Crowley 2002). Merger constructions, as exemplified by the coverb construction, never have this function.

Other characteristic functions of serial verb constructions are the introduction of information on direction (18) and manner (19). 5 That is, functions which are again realised by adjuncts in other languages.

5 Crowley (1987: 42-47) provides evidence that the Paamese constructions in (18)-(22) are monoclausal serial verb constructions and not multi-clausal conjoined constructions. 
(I8) ni-suvulu

ni-hiitaa

netano

ISG:DIST.FUT-climb.down

ISG:DISTFUT-descend

down

'I will climb down.' (Paamese - Crowley 2002: 68)

$\begin{array}{llc}\text { (I9) inau na-muasi-ko } & \text { O--gaiho } \\ \text { ISG } & \text { ISG:REAL-hit-2SG } & \text { 3SG:REAL-hard } \\ \text { 'I hit you hard.' (Paamese - Crowley 2002: 6I) }\end{array}$

Aspect distinctions are often realised by means of serial verbs:

(20)
teeviti Ø-mule
Ø-metau
David
3SG:REAL-stay
3SG:REAL-afraid
'David is (habitually) afraid.' (Paamese - Crowley 2002: 78)

Serial verb constructions also commonly convey all kinds of resultative and causative meanings:

(2I)

$\begin{array}{llll}\text { inau nuas } & \text { vuas he:mat } \\ \text { inau ni-uasi } & \text { vuasi hee-mate } \\ \text { ISG rSG:DIST.FUT-hit } & \text { pig } & \text { 35G:DiST.FUT-die } \\ \text { 'I will hit the pig to death.' (Paamese - Crowley 2002: 55) }\end{array}$

(22)

$\begin{array}{ll}\text { ne-sakini-e } & \text { ko-musau } \\ \text { ISG:REAL-cause-3SG } & \text { 2SG:REAL-sing }\end{array}$

'I made you sing.' (Paamese - Crowley 2002: 8I)

\subsection{Constraints on monomorphemic predicates}

We have proposed that the differences between merger constructions and coindexation constructions follow from differences in the way that the constituents contribute to the overall complex predicate. Specifically, we propose that merger constructions class fundamentally with monomorphemic predicates. We group merger constructions and monomorphemic predicates together in a class of 'simplex event' constructions.

In this section, we argue that there are constraints on simplex events, following similar proposals in the tradition of Dowty (1979); e.g. Van Valin and LaPolla (1997), Rappaport Hovav and Levin (1998), and Levin and Rappaport Hovav (2005). Our analysis relies on Jackendoff's (1990, 1997, 2002) theory of Lexical Conceptual Structures (hereafter LCS). LCSs are formal decompositions of the meaning of event lexemes, constructions, and clauses. Jackendoff recognises that conceptual structure cannot be approached from a single perspective. Levin and Rappaport Hovav (2005: 78-130) discuss three of the principal approaches - which they call 'localist', 'causal' and 'aspectual'. The localist approach claims explicitly that 
all verbs can be represented in terms of predicates of location or motion (Levin and Rappaport Hovav 2005: 80). Early work representing this position includes Gruber ( 1965 ) and Jackendoff ( 1983 ). In later work Jackendoff (1990: 126) proposes that LCSs have distinct 'tiers', which represent distinct bases for the analysis of conceptual structure. He proposes an 'action tier' for Actor-Patient relations - the causal approach - and a 'thematic tier' for motion and location - the localist approach. Jackendoff (1990) does not propose a representation for the aspectual approach (though Jackendoff (1991, 1996) contain developments of such an approach), but as we will see (section 2.6), there is evidence that there must be a level of representation for aspect in lexical conceptual structure.

In this chapter, we are principally concerned with representations on the thematic tier. This is because relations of motion and location are the most frequent criteria in distinguishing between the two classes of complex predicates. This in turn is presumably because relations of motion and location are more commonly constant across the various appearances of a particular lexeme than are aspectual or causal relations (Gruber 1965). A classic example is the verb 'hit'. In all uses, there is motion from the location of one entity $x$ towards the location of another entity $y$. Neither aspectual nor causal relations are constant across all uses of 'hit'. We do not, however, intend to deny the importance of aspectual and causal relations, and we discuss them at various points.

The thematic tier consists of 'conceptual functions', predicates with very general meanings and their arguments. The arguments of the conceptual functions correspond to the arguments (overt or implicit) of a clause. Conceptual functions can themselves be the arguments of other conceptual functions. The major conceptual functions relevant to event structure are $\mathrm{BE}, \mathrm{BECOME}, \mathrm{CAUSE}$ and MOVE. ${ }^{6}$ These functions are similar in relevant respects to the sets of basic functions found in other work in predicate decomposition, such as Dowty (I979), Rappaport Hovav and Levin (1998), Van Valin (1993), and others.?

We propose that there are two major constraints on simplex event structures, whether realised as monomorphemic predicates or as merger constructions.

(23) The major Predicate functions - CAUSE, BECOME, MOVE, $\mathrm{BE}$ - may appear only once in the LCS of the overall complex predicate.

- Jackendoff (1990: 88-89) distinguishes two motion functions - a MOVE function and a GO function. The difference between the two is that the GO function has a Path expression, whereas the MOVE function does not. We discuss this issue and others more fully in section 2.5 .

' See especially Levin and Rappaport Hovav (2005) for an overview of work in this tradition. 
(24) The major Predicate functions must appear in the following sequential order:

CAUSE $>\left\{\begin{array}{l}B E C O M E>B E \\ M O V E\end{array}\right.$

We propose that stative predicates are characterised by a $\mathrm{BE}$ predicate, whereas activity predicates are characterised by a MOVE predicate (Jackendoff 1990). We propose that the distinctions between the various types of activities are coded by subscripting the MOVE predicate with a manner specification. Within the class of events involving activity predicates, there is a basic opposition between those involving a Path expression (motion predicates), and those not involving a Path expression. Other categories of events, such as achievements and accomplishments may be derived by the application of additional predicates such as BECOME and CAUSE.

Given the constraints in (23) and (24), we can derive the following simplex event structures: 8

(25) Intransitive state predicates, e.g. 'be wet'

$[$ Staie $\mathrm{BE}([$ Thing $],[$ place $])]$

(26) Intransirive activity predicates, e.g. 'tremble'

$[$ Event $\operatorname{MOVE}([$ Thing $])]$

(27) Intransitive motion predicates, e.g. 'walk'

$$
\left[E_{\text {vert }} \operatorname{MOVE}\left(\left[\text { Thing }_{\text {Th }}\right],\left[\text { Path }_{\text {at }}\right]\right)\right]
$$

8 Levin and Rappaport Hovav (1998: 108) propose a similar set of 'event structure templates' for simple predicates, following on from the agenda-setting work of Vendler (1967) and Dowty (1979), though they distinguish just five basic types (state, activity, achievement, and two kinds of accomplishment, corresponding to our (25), (26), (28), and (31), though we do not distinguish between their 'internally caused' and 'externally caused' accomplishments). They do not distinguish the various transitivity sub-types of activities and accomplishments, nor between motion and non-motion activities without further augmentation of the template -'event structure templates may be freely augmented up to other possible templates in the basic inventory of event structure templates' - but we feel the two accounts are broadly comparable. 
(28) Intransitive accomplishments, e.g. 'sink' and achievements, e.g. 'shatter'

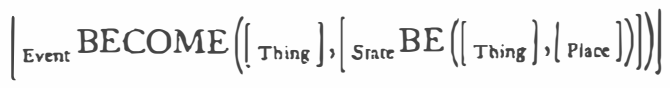

(29) Causatives of intransitive activity predicates, e.g. 'shake something'

$$
\left.\mid E_{\text {vent }} \operatorname{CAUSE}\left([\text { Thing }],\left[\text { Event } \operatorname{MOVE}\left(\left[\text { Thing }_{]}\right]\right)\right]\right)\right]
$$

(30) Transitive motion predicates, ${ }^{9}$ e.g. 'walk a dog'

$$
\left[\text { Event } \operatorname{CAUSE}\left([\text { Thing }],\left[\text { Event }_{\text {MOVE }}\left([\text { Thing }],\left[\text { Psth }_{\text {Ts }}\right]\right)\right]\right)\right]
$$

(3I) Transitive accomplishment predicates, e.g. 'build a house'

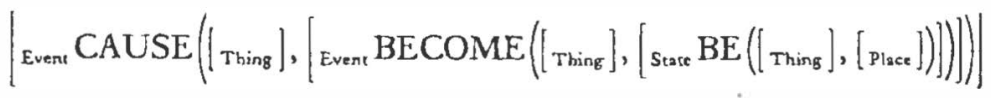

There is one other licit simplex event LCS, but its structure differs from those in (25)-(3r). Unlike all of these constructions, it involves simultaneous functions - MOVE and BECOME. This special merger construction is examined in section 2.6 .

Allowing for this special construction, we propose that there are no licit LCSs for simplex event structures, beyond those listed in (25)-(3I). The constraints predict that the following kinds of structures should not be licit simplex event structures, either because they involve an illicit ordering of predicates, or because they involve duplication of predicate functions.

(32) Inceptives of activity, e.g. 'start to laugh'

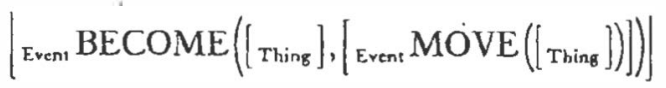

9 This entails that the object position of transitive activity verbs like 'hit' does not find a straightforward reflection in the structure, a problem also noted by Levin and Rappaport Hovav (2005).

10 We have addressed only the major predicate functions here. We omit from consideration minor types such as 'EXT' (extend), 'CONF' (confgure) etc., as well as adjuncts, and additional possibilities for the 'Path' argument discussed in Jackendoff (1990). 
(33) Inceptives of motion, e.g. 'start to go'

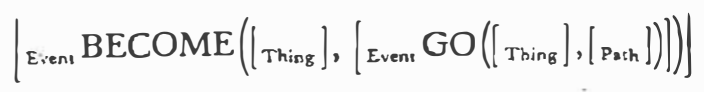

(34) Associated state with state, e.g. 'be sitting drunk'

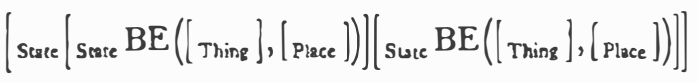

(35) Associated state with activity, e.g. 'be sitting laughing'

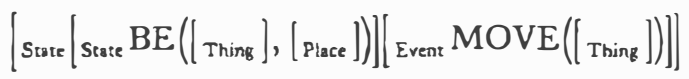

(36) Associated motion with state, e.g. 'go along drunk'

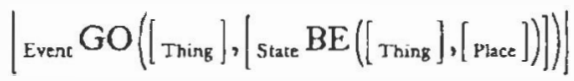

(37) Associated motion with activity, e.g. 'go along laughing'

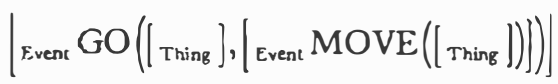

(38) Associated motion with causatives and inceptives of a transitive verb, e.g. 'go along causing to/starting to eat'

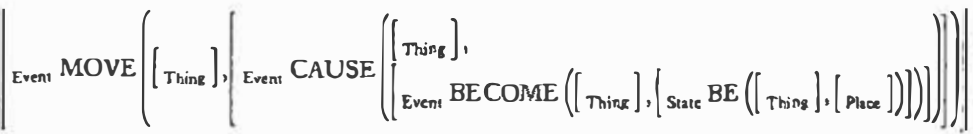

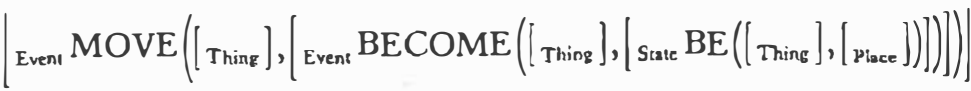

Because these are not licit simplex event structures, we predict that in no language should we find such events expressed as monomorphemic predicates. We also predict that merger constructions should not be able to produce such event structures. Coindexation constructions, on the other hand, may be able to code all or any of (32)-(38), depending upon the operation of other constraints. We show that this is the case in section 7 . 


\subsection{The formal structure of merger}

In the preceding sections 2.3 and 2.4 , we showed that the semantic range covered by coverb constructions is a subset of that covered by serial verb constructions. In this section, we show how this difference in ranges follows from the differing ways that predicate information is combined in the two constructions.

Following Wilson (1999), we propose that merger takes place at the level of conceptual structure. The LCSs of two predicates merge to produce a single LCS. The general principle is that predicate information from the constituents is maintained in the merged predicate. Wilson presents the following description of conceptual merger.

What actually happens is that the coverb's LCS fuses into the verb's LCS wherever it happens to fit. Where it happens to fit will depend upon the particular LCSs involved. For instance, the light verb - ge- 'put $2 T^{\prime}$ ' contains a State as part of its LCS. The coverb guk 'sleep' is a State. So when the LCSs are fused together, the LCS of $g u k$ is fused with the State entity in the LCS of ge-. But the LCS of bort 'die' consists of an Event which is expanded as a BECOME function. So when it is fused with the LCS of -ge-, it is fused with the BECOME Event there, and not with the State. In short, I propose that the LCS of the coverb is fused with some part of the LCS of the inflecting verb with which it can unify. (Wilson 1999: $141-42$ )

Using the examples from Marra preceding, repeated here, we present the basic structure of conceptual merger.

(39) birli=nga- $\varnothing$-ganji

go.in = ISG.S-3SG.O-TAKE.PP

'I put it in(side).'

(40) birli=gu-lini

go.in $=3$ SG.S-GO.PC

'He went in.'

The LCS of the Marra coverb birli 'go in', following Jackendoff (1990: I79) can be characterised as in (4I).

(4I) birli 'go in': [Event $\operatorname{MOVE}\left(\left[_{\text {Thing }} x\right]\right.$, [ parh $\left.\left.\left._{1 N} \mathrm{IN}\right]\right)\right]$

The LCS of the verb lini is given as (42).

(42) lini 'go': [Event MOVE ([Thing $x],\left[\right.$ Past $\left.\left.\left._{\text {pat }}\right]\right)\right]$

The LCS of the light verb ganji is given as (43).

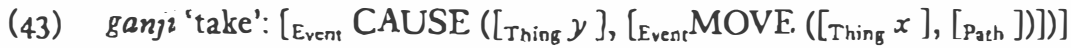


When coverbs and finite verbs merge, the LCS of the finite verb takes the LCS of the coverb as an argument, at the highest shared predicate function. Since the LCS of birli contains a MOVE function, it can merge successfully with a light verb containing a MOVE function. In the case of ganji, this MOVE function is in turn an argument of a CAUSE function, and hence the only argument of MOVE becomes an internal argument of CAUSE. This gives us the syntactic result that birlitganji is a transitive verb where the only argument of birli surfaces as the object of the CAUSE predicate.

(44) birlitganji 'put in': [Exrent CAUSE ([Thing $]$, [MOVE ([Thing $x$ ], [Path $\mathrm{TN}])])]$

In the process of merger, the LCS of birli merges with the LCS of ganji at the point where the two LCSs share a predicate in common. As already explained, this is at MOVE. When birli combines with lini 'go', the result is straightforward. We simply get the LCS that birli has anyway, with the only argument of MOVE surfacing as the subject of the coverb construction.

(45) birli+lini 'go in':

[Event $\operatorname{MOVE}\left(\right.$ Thing $\left.^{*}\right],\left[\right.$ Pach $\left.\left.\left._{\text {IN }} \mathrm{IN}\right]\right)\right]$

Having a predicate function in common is not, however, sufficient to ensure a successful merger. We may consider the following Wagiman examples."

(46) bak 'break':

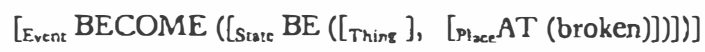

(47) $y$ 'be':

[siate $B E([$ Thing $],[$ place $])]$

(48) "bak yu 'be broken':

[Staste $B E([$ Thing $],[$ plaze $A T$ (broken) $)])]$

The bak 'break' and $y u$ 'be' predicate have a common predicate function BE. However, as Wilson (I999: I44, I5I) points out, this merger fails because the lexical structure of the coverb is not preserved in the merger construction. Wilson uses Lexical-Functional Grammar to encode this as a constraint on merger. We express the constraint as follows.

(49) The LCSs of the finite and non-finite constituents must be merged at the level of the highest major predicate function in the LCS of the non-finite predicate(s).

The constraint expresses the intuition that the central motivation for merger constructions is to enable the non-finite constituent to head a clause. Consequently, its conceptual structure is maintained in the merged LCS.

In addition to this constraint, the predicates resulting from merger, being simplex event predicates, are subject to the constraints in (23) and (24), already discussed. The effects of these constraints may be illustrated

"Except where otherwise indicated, Wagiman examples are taken from Harvey's fieldnotes. 
by comparing the acceptable combination of the motional activity coverb birli 'go in' with the finite verb lini 'go', against the unacceptable combination of another non-motional activity coverb mir 'whistle' with the same finite verb.

(50)

$$
\begin{aligned}
& \text { *wir }=\text { gu-lini } \\
& \text { whistle=3SG.S-GO.PC } \\
& \text { 'He went along whistling.' }
\end{aligned}
$$

The obvious interpretation of this combination is the associated motion meaning 'go along whistling', which is perfectly semantically and pragmatically plausible. However, it is not possible to compose this meaning within a merger predicate.

$$
\begin{aligned}
& \text { Dir 'whistle': [Event } \left.M O V E_{<\text {wHIST). }}\left(\left[\text { Thing }_{\text {Th }}\right]\right)\right] \\
& \text { (52) lini 'go': } \\
& \text { [Event } \left.\operatorname{MOVE}\left(\left[\text { Thing }_{\text {e }}\right],[\text { path }]\right)\right] \\
& \text { [Event } \left.\operatorname{MOVE}_{<\text {wristLE }}\left(\left[\text { Thing }_{\text {Th }}\right],[\text { Path }]\right)\right]
\end{aligned}
$$$$
\text { (53) * wir+lini: }
$$

As shown in (53), the result of merging 'whistle' and 'go' is the semantically incoherent 'move along a path by means of whistling'. In order to express the associated motion meaning, two simultaneous MOVE predicates are required - one describing the whistling and the other describing motion along a path. However, the constraint in (23) prohibits multiple appearances of the MOVE predicate. Consequently, non-motion activity coverbs cannot generally combine with a motion verb in Marra. ${ }^{12}$

The ungrammaticality of (53) does not, however, follow from any inherent prohibition on the merger of non-motion functions with motion functions. Rather it follows from the real-world implausibility of the resultant combination. We may consider the following examples from Wagimar.

$$
\begin{aligned}
& \text { warratj-ja ga-ba-yu } \\
& \text { dance-ASP PRES-3PL.S-be stand-ASP }
\end{aligned}
$$

$$
\begin{array}{lll}
\text { jahan-gu } & \text { warratj-ja } & \text { g-i-ya } \\
\text { what-DAT } & \text { dance-ASP } & \text { PRES-2SGS-go }
\end{array}
$$

'Why are you dancing along/going dancing along?' (Wilson I999: 107)

12 It should be noted that this combination is unacceptable only in the interpretation 'go whistling'. In other north Australian languages, the 'go' verb has an additional light verb entry ' $D O / B E$ for a long time' (e.g. Jaminjung; Schutlze-Berndt 2000: 265). In these languages the combination of activity coverb lacking a Path expression with the 'go' verb is perfectly acceptable in the meaning ' $\mathrm{DO}$ activity for a long time'. 


warratj-ja $\quad \varnothing$-di-nginy
dance-ASP $\quad$ 3SGS-come-P.PFV
'She came dancing.' (Wilson 1999: 107)

The coverb Doarratj 'dance (of wornen)' may plausibly describe both motional and non-motional situations. When describing a non-motional situation - dancing on the spot - it takes the 'be' verb. ${ }^{3}$ When describing a motional situation, it takes either the 'come' or the 'go' verb. With changes in real-world circumstances other mergers might becorne plausible. For example, in the weightless environment of space a sentence like 'She sneezed herself into the next compartment of the space capsule' might be perfectly acceptable. In this case the movement of sneezing would be sufficient to engender a path.

Our analysis of the class of activities differs somewhat from that of Jackendoff. Jackendoff (I990: 88-9I, 223-25) proposes two activity functions - a MOVE function and a GO function. The difference between the two is that the GO function has a Path expression, whereas the MOVE function does not. This opposition is different in kind from the other oppositions between predicate functions. Predicate functions are not otherwise distinguished by whether or not they require or prohibit a particular expression. We suggest that this is not a well-motivated basis for opposition.

Further, the analysis that manner of motion [MOVE] is necessarily conceptually distinct from motion along a path $[\mathrm{GO}]$ is problematic. Some predicates, at least, seem inherently to involve both. The paradigm example is 'walk'. This is a manner of motion, but it must necessarily be realised along a path. While it is possible to run, hop, skip, jump, and dance on the spot, it is not possible to walk on the spot.

Proposing a distinction between MOVE and GO functions also requires additional formal theoretical structure. In order to describe situations where a manner of motion predicate encodes a path, Jackendoff requires adjunction rules which add a GO function (1990: 224).

(57) GO-adjunct rule (version 2)

$\left[{ }_{\gamma p} V_{h} \ldots P P\right]$ may correspond to

$$
\left[\begin{array}{l}
\operatorname{GO}\left([\alpha],\left[{ }_{p_{2} \text { th }}\right]\right) \\
\operatorname{AFF}\left([]_{i}^{\alpha},\right) \\
{\left[\operatorname{WITH/BY}[\operatorname{MOVE}([\alpha])]_{h}\right]}
\end{array}\right]
$$

13 The 'be' verb has two meanings in Wagiman. One is to signal stativity, the other to signal atelicity (section 2.7). In (54), it signals atelicity. 
The rule, as presented by Jackendoff, requires an overt expression of the endpoint of the motion - the PP in Jackendoffs formalisation. It is unclear how Jackendoff would account for examples such as (55), where there is no overt endpoint expression. We may also note that this adjunction rule has no overt linguistic realisation in many cases (Jackendoff 1990: 224).

Given these issues, we depart from Jackendoff's analysis and"propose that there is only a MOVE function, common to all activity predicates. This MOVE function may license an optional Path expression. Whether an individual predicate does license a Path expression is subject to real-world considerations and to language-specific variation.

In those cases where a Path expression is not licensed, a non-finite constituent encoding a MOVE predicate must select a verb other than 'go' or 'come' in order to construct a successful merger. In Marra, a coverb such as mir 'whistle' selects the mindini 'do/say (thus)' verb (see section 2.7).

(58) wir=nga-mindini

whistle $=$ I SG.S-DO.PC

'I was whistling.'

We propose that this is possible because the verb 'do' is the generic activity verb, being simply a MOVE predicate, without further specification as to the manner of movement.

(59) mindini 'do':

[Event $\operatorname{MOVE}\left(\left[\right.\right.$ Thing $\left.\left.\left._{\text {g }}\right]\right)\right]$

(60) Dir+mindini 'whistle': [Event $\left.M O V E_{<\text {whISTLE }}\left(\left[_{\text {Thing }}\right]\right)\right]$

In merger constructions, the finite predicate is commonly less extensively specified than the non-finite predicate. Activity coverbs normally have either a manner subscript, e.g. <WHISTLE>, or a specification in the Path expression, e.g. IN. The 'go' verb, on the other hand, has neither. However, as Wilson (1999: 140) points out, it is not necessary that finite predicates should bear less specification than non-finite predicates in some quantifiable way. The following examples from Wagiman illustrate this.

(6r)

$$
\begin{array}{ll}
\text { durdut-ta } & \text { ba-di-nya } \\
\text { run-ASP } & \text { 3PLS-come-PAST }
\end{array}
$$

'They came running.'

(62) durdut bula-ndi

run:PFV leave-PAST (Wilson 1999: 155-56)

'She ran away from him/She ran away and left him.'

The LCSs of these predicates are set out in $(63)-(65)$ :

(63) di 'come': [Event $\operatorname{MOVE}\left(\left[_{\text {Thing }}\right]\right.$, [path $_{\text {TOWARD }}$ ([place HERE])])] 


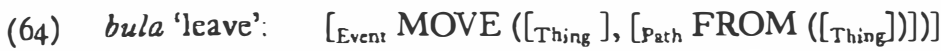

(65) durdut 'run': [Event $M O V E_{<\mathrm{RUN}>}\left([\right.$ Thing $],\left[\right.$ Path $\left.\left.\left._{\text {Th }}\right]\right)\right]$

The merged LCSs are set out in (66) and (67):

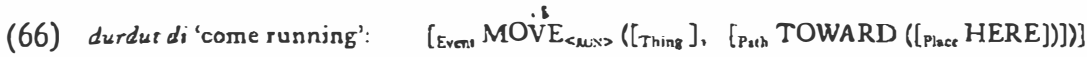

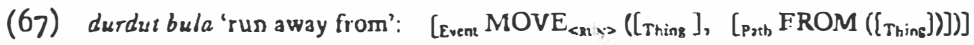

The verbs di 'come' and bula 'leave' do not have light verb entries in Wagiman. Further, it is not evident how their degree of specification might be quantified as against the coverb durdut 'run'. Nonetheless, neither of these factors prevents them from entering into merger constructions.

In keeping with the general principle of preserving predicate information, merged structures may involve compound functions, where these are plausible, as in (69), where the DOWN function from the coverb lek 'move down' is compounded with the TOWARD function from the finite verb $d i$ 'come'.

(68) lek 'move down': [Event MOVE ([Thing ], [Pach DOWN])]

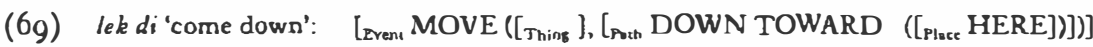

\subsection{Merger and motional inchoatives}

The merger constructions discussed in section 2.5 all involve sequential relations among the major predicate functions. The constraint in (24) generally prohibits simultaneous relations among the major predicate functions. However, there is one circumstance where the constraint docs not prohibit simultaneous relations. This is when motion to an endpoint induces a change of state in an entity contemporaneous with that endpoint. In this case, merger can support simultaneous MOVE and BECOME predicates.

We provide examples of this type of merger construction from Wagiman (Wilson, 1999: 104, 105, 140):

(70) bak

O-linyi-ng lari

break 3SG-fall-PP arm

'He fell and broke his arm.'

[lit. 'His arm broke in falling.']

(7I) menuny burbur bak ga-ba-du-n

maybe wing break NP-3PLS-cut-PR

'Maybe they break its wings by cutting them. ${ }^{n_{4}}$

14 Wilson translates this sentence as 'They broke its wing by spearing', but 'spear' is a separate verb re, while the verb used here, $d u-$, centrally refers to cutting, not spearing. 
The coverb bak 'break' is an inchoative coverb (Wilson 1999: 102-106), and has the following LCS:

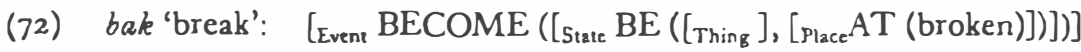

The LCSs of the 'fall' and 'cut' verbs are as follows:

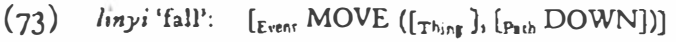

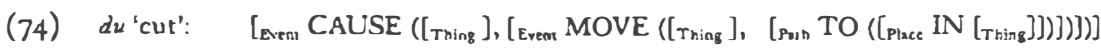

The LCS of the coverb may be merged with the LCSs of these verbs to produce the following:

(75) bak linyi 'break by falling': [Evoni MOVE ([Thing ],, [ath DOWN])]

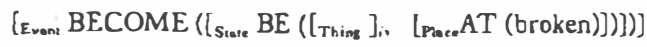

(76) bat $d u$ 'break by cutting':

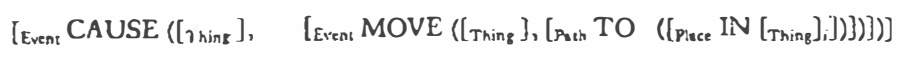

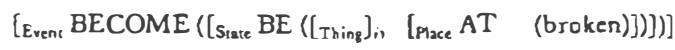

The BECOME function is monovalent, and its argument must be coindexed with either the argument of the MOVE function or the argument of the TO function. If the TO function has no argument then there is no choice. If the TO function has an argument, then considerations of sinultaneity determine coindexation. The MOVE and BECOME functions are simultaneous at the endpoint of the motion, rather than during its trajectory. Consequently, if there are distinct trajectory and endpoint arguments, the argument of the BECOME function is coindexed with the endpoint argument.

We propose that simultaneous MOVE and BECOME functions may only appear in a merger construction when they are independently supplied by the contributing constituents. If they are not independently supplied then the merger construction will not be interpretable with an inchoative meaning. In the available materials, there are no examples of a stative coverb merging with a motion verb and the resulting merger construction having an inchoative interpretation. We predict that such combinations cannot be so interpreted.

(77) mele-ma Ø-linyi-ng black-ASP 3SGS-fall-PP

*'S/he became black by falling.'

This interpretation is not impossible for real-world reasons. A situation where a white-skinned person fell into a large puddle of black mud could plausibly be described this way. 
In addition to the straightforward examples of motion inchoatives, such as (70) and (71), there are other less immediately evident examples. The following examples are from Ngaliwurru (closely dialectal with Jaminjung Schultze-Berndt p.c.).

(78) darnku gani-yu full 3 SGS.3SGO-do.PP

'He has become full.' ('He is full/He has had a feed.')

(79) darnku gani-minda-ny

full 3SGS.3SGO-eat-PP

'He has eaten (food) to becoming full.' ('He has eaten till full.')

(80) darnku gani-ngarna-ny

full 3SGS.3SGO-give-PP

'She gave him (food) and he become full.' ('She fed him./She gave him a feed.')

The coverb darnku is an inchoative coverb 'become full', and not a stative coverb 'be full'. This is shown by the fact that it occurs in intransitive constructions with the 'do, say, become' verb and not the 'be' verb. The merger constructions in (79) and (80) are motional inchoatives. Their LCSs are set out following:

[CAUSE $([x]$,

[CAUSE $([\gamma]$
[MOVE ([food] [TO (stomach of $[x])])])]$

[BECOME $([\mathrm{BE}([x],[\mathrm{AT}($ full $)])])]$

[MOVE ([food] [TO (stomach of $[x])])])]$

[BECOME $([\mathrm{BE}([x],[\mathrm{AT}(\mathrm{fuJl})])])]$

\section{7 'Be' and 'do' verbs}

Any analysis of complex predicate constructions necessarily involves some consideration of how these are to be distinguished from auxiliary constructions. Auxiliary verbs are traditionally analysed as nonpredicational. Unlike light verbs, they lack an argument structure. Consequently, monoclausal constructions involving an auxiliary verb and a main verb are not complex predicate constructions. Thus the English perfect $H A V E+V$-en and progressive $B E+V$-ing constructions are not complex predicate constructions, as 'have' and 'be' have no effect on argument structure in these constructions. Rather, they provide aspectual information.

In English, there is a very clear distinction between auxiliaries, which have no argument structure, and light verbs, which do have an argument structure. The two classes may co-occur - 'She should have given you an 
answer'. Butt (this volume) shows that the two classes are similarly distinct in Urdu and may co-occur. She argues that a distinction must be drawn cross-linguistically between 'auxiliary' and 'light verb'.

However, in many languages with the coverb construction, it is not immediately evident whether this distinction is applicable. The issue as to whether the distinction is applicable or not arises in relation to verbs translated with the classic auxiliary meanings 'be' and 'do'. Verbs translated with these meanings have a wide range of uses, which vary somewhat from language to language, and determining their language specific meaning is complex. A full analysis of the semantics of 'be' and 'do' verbs is beyond the scope of this chapter.

The only detailed discussion of these verbs in a language with the coverb construction is Schultze-Berndr (2000: 129-33, 225-27, 349-70, 449-57) on Jaminjung. We consider the Jaminjung data here, as it is illustrative of the general patterns in languages with the coverb construction.

Schultze-Berndt suggests that there is a distinction between auxiliary function and light verb function, at least for the 'be' verb. We may consider the following example, where the coverb takes the continuous suffix -mayan.

(83)

$\begin{array}{lllll}\text { en } & \text { janyungbari } & \text { burlug-mayan } & \text { ga-yu } & \text { gugu } \\ \text { and another } & \text { drink-CONT } & \text { 3SGS-BE.PRES } & \text { water }\end{array}$

'And the other one is drinking water.' (Schultze-Berndt 2000: 195)

In this case the Jaminjung construction burlug-mayan ga-yu and its English translation is drink-ing are morphologically isomorphic. Both involve a derived progressive/continuous non-finite form burlug-mayan $\sim$ drink-ing and a finite 'be' verb.

The two constructions are not only morphologically isomorphic, they also appear to be predicationally isomorphic. The Jaminjung 'be' verb appears to lack an argument structure. The coverb burlug 'drink' is apparently bivalent. Bivalent coverbs cannot otherwise combine with monovalent verbs (49). The 'be' verb in (83) signals atelic aspect (Schultze-Berndt 2000: 226). Schultze-Berndt therefore proposes that the 'be' verb is an auxiliary in this construction.

However, she states that the analysis of continuous coverbs and this auxiliary interpretation requires further research (2000: 132). She presents two reasons why further research is required. First, with non-continuous coverbs, the 'be' verb behaves straightforwardly as a light verb:

(84) bayirr

ga-yu

be.supported 3SGS-BE.PRES

'It is supported.' (Schultze-Berndt 2000: 22I)

Second, continuous coverbs do not require the 'be' verb in Jaminjung: 


$$
\begin{array}{lcc}
\text { jarr-mayan=biya } & \text { gan-arra-m=ngarndi } & \text { ba-ngawu } \\
\text { put.down.one-CON:T=NOW } & \text { 3SGS.3SGO-put-PRES=SFOC2 } & \text { IMP-see }
\end{array}
$$

'She keeps putting them down one at a time, look!' (Schultze-Berndt 2000: 13I)

Polyvalent coverbs such as jarr-mayan 'put.down.one-CONT' may combine with polyvalent verbs such arra 'put'. Given that the apparent mismatch in $(83)$ is not categorically required, we suggest that it is not a sufficient basis for distinguishing two morphosyntactic functions of the 'be' verb.

Further, we propose that there are in fact no mismatches in Jaminjung where a bivalent coverb combines with a monovalent verb. The examples of this mismatch listed in Schultze-Berndt (2000) all involve the coverbs burlug 'drink' or thamaya 'eat'. Examination of the combinatorial possibilities of burlug show that it is not best translated with a bivalent 'drink' meaning. Rather its distribution exactly parallels that of darnku 'become full of food' $(78-80)$. As such it is better translated with a monovalent meaning something like 'become full of water'. Similarly, the coverb thamaya codes the intransitive 'eat' meaning. The transitive 'eat' meaning is coded by the finite verb minda 'consume'.

Nonetheless, it must. be recognised that the semantic contribution of 'be' in (83) is distinct from its contribution in (84). This must be formally modelled with two distinct lexical entries - one for stative 'be' and the other for atelic 'be'. As discussed in section 2.4, Jackendoff does not provide a formal representation for aspectual information in lexical conceptual structure. In his model, it would presumably be an independent tier. It would be on this tier that the aspectual information from 'be' in (83) would be integrated into the LCS of the merger construction. In the absence of any formalisation of this tier, we do not examine this issue further.

The semantics of the 'do' verb are particularly complex (Schultze-Berndt 2000: 349-70). In Jaminjung, it conveys the meanings 'become' and 'say' as well as 'do'. This set of meanings is attested in a heterogeneous range of languages, particularly the 'do/say' combination (Schultze-Berndt 2000: 358-59). This argues that it is not a chance collocation, but follows from general principles. Schultze-Berndt (2000: 358) proposes that this verb has the following meaning.

$$
\mathbf{x} \text { internally causes, and gives immediate evidence of, an event } E
$$

The Event in this representation could be an utterance, a cognate object noun ('speech/word'), or a coverb. She proposes, further, that 'do' is the default light verb in Jaminjung (2000: 368 ). If there is a positive motivation for another light verb, then 'do' is not used.

The LCS formalisms adopted in this chapter do not allow for default defined meanings such as that in (86). Rather, meanings must be positively determined. Given that the core meaning of this verb is an 
unspecified activity, we propose that its representation is as a simple MOVE predicate.

(87) do: [Event $\operatorname{MOVE}([$ Thing $])]$

In many languages, including Jaminjung, the same form has another lexical entry with an inchoative meaning.

(88) do:

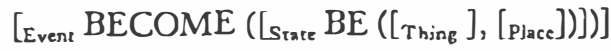

This additional lexical entry is licensed by universal metaphor, where inchoative relations are analogically assimilated to motional relations Uackendoff I990: 25).

The analysis of the 'be' and 'do' verbs presented here is undoubtedly preliminary in nature, and we agree with Schultze-Berndt that much further research is required. However, we may note that there is no clear evidence for an opposition between an auxiliary category and a light verb category in Jaminjung. This appears to be true in many languages with the coverb construction. In the absence of clear evidence for this opposition, we analyse coverb constructions as involving light verbs only. ${ }^{15}$

\subsection{Monoclausality: the dissociation between simplex event structure and clause structure}

At this point, it is useful to reconsider the notion 'complex predicate', with which we started this chapter, now that we have introduced the different types of constructions equally labelled 'complex predicates' in the literature. Jackendoff's (1990) model allows us to represent the relation between Lexical Conceptual Structure and syntax in a more sophisticated way. It appears that the parameters 'constituting a licit simplex event structure' and 'being a clausal predicate' must be allowed to vary independently. This produces at least four kinds of LCS:Syntax relations, shown in Figure 2.r.

Type (a) represents a simple, monomorphemic predicate heading a single clause. Type (b) represents the merger construction, where two predicates jointly contribute to an event which corresponds in its semantic range to the events realised by monomorphemic predicates. Type (c) is a standard construction where multiple predicates are realised by multiple clauses. Type (d) is a multi-predicational, but monoclausal construction, as in the classic serial verb construction. In this case, we regard the conceptual structure as one in which there are multiple events. This is contrary to the commonly held view, as summarised by Aikhenvald (2006: I).

is We note that further research may establish that there are some languages where the verb in a coverb construction is clearly an auxiliary. 
Type (a): simple, monomorphemic predicate - monoclausal structure

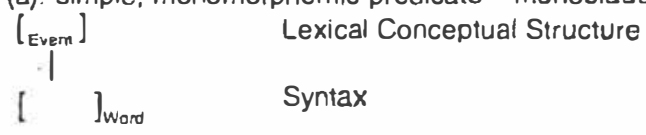

Type (b): classic coverb construction - mohoclausal structure

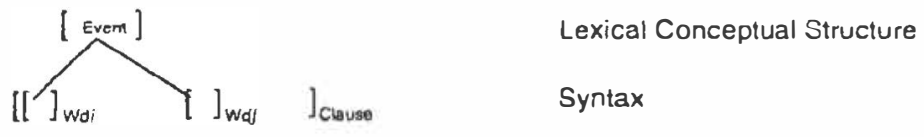

Type (c): multiple prodicates - multiple clauses

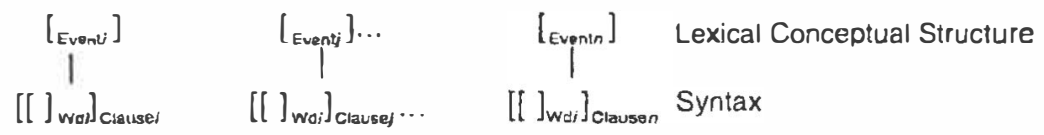

Type (d): multi-predicational, but monoclausal construction - classic SVC

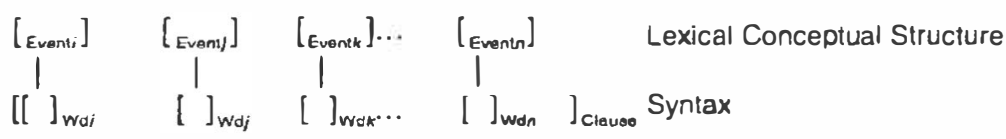

Figure 2.I Types of LCS-syntax relations

A serial verb construction (SVC) is a sequence of verbs which act together as a single predicate, without any overt marker of coordination, subordination, or syntactic dependency of any other sort. Serial verb constructions describe what is conceptualised as a single event.

In terms of permissible event types and sequences, classic serial verb constructions class with multi-clausal structures. They differ from multi-clausal structures in that serial verb constructions are always constrained in terms of some argument coindexation requirement. ${ }^{.6}$

\subsection{The range of oppositions between merger and coindexation constructions}

We have proposed that coindexation constructions are multi-predicate constructions and consequently not subject to the constraints which affect merger constructions. This leads to a number of differences both obvious and less immediately evident. Firstly, coindexation constructions may permit

${ }^{16}$ It is, however, clearly necessary to recognise at least three different types of coindexation relationships between predicates below the level of completely independent sentences. Theories of syntax need to accommodate nuclear junctures, core junctures, and clause chaining, in addition to completely independent sentences (Foley and Olson 1985). Foley (this volume) discusses these issues. 
multiple instances of one of the major predicate functions. As such, coindexation constructions may code causatives of transitives.

$$
\begin{aligned}
& \text { nayp }{ }^{\text {hon }} \text { hây } t^{\text {tháhan }} \mathrm{k}^{\text {hâ }} \text { nákrian } \\
& \text { general give soldier kill student }
\end{aligned}
$$

By contrast, in languages with the merger construction, complex predicates cannot form the causatives of transitives. The only way of forming the causatives of transitives is with a biclausal construction, as in (90).

$\begin{array}{llllll}\text { nan-gu-yi } & \text { nani } & \text { na-boj } & \text { judum=nga-mi } & \text { nana rayi } \\ \text { ISgO-3SGS-tell.PC } & \text { MA.OBL } & \text { MA.OBL-boss } & \text { shoot=ISGS-DO.FPUN } & \text { MA.REL bird }\end{array}$

'The boss told me to shoot those birds.'

In coindexation constructions, there is theoretically no upper limit on the number of verbs in a single clause, subject to pragmatic and semantic wellformedness. While not common, examples with three or more verbs may be found, as in (9I):

(9I) $\begin{array}{lllllllll}\text { da } & \text { mong la saao de bing bare ko ma } \\ \text { 3.s } & \text { PAST } & \text { stir FACT food take put leave give me }\end{array}$
'S/he made food and left it there for me.' (Dagaare - Bodomo, I997: 15)

In merger constructions, the maximum attestation is two non-finite predicates. This is illustrated in the following example from Jaminjung (SchultzeBerndt, 2000: 122):

(92) munuwi-ni gabarl yurl gani-mangul wirib bee-ERG go.close chase 3SG:3SG-HIT.PST dog

'The bees came up close chasing him, the dog.'

[lit. 'The bees chased him up close, the dog.']

In all examples of this type - two coverbs and a single verb - one coverb modifies the other. Many languages, such as Marra, do not allow more than one coverb per clause.

Coindexation constructions permit the major predicate functions to appear in sequential orders other than that specified in (24).

(93) dbëhna-noh-me-r

sick-die-REM.PAST-3SGM

'He was sick and died.' (Alamblak - Bruce 1979: 242)

In (93), the BE (sick) predicate precedes the BECOME (BE (AT dead)) predicate. Coindexation constructions also permit simultaneous 
temporal relations between all the major predicate functions. The following examples are from Ngan'gityemerri, with (94) involving two simultaneous MOVE predicates, and (95) involving simultaneous MOVE and $\mathrm{BE}$ predicates.

(94) nga-ganim-fif

$\therefore$

I SGS-go.PR-smoke

'I'm going along smoking.' (Ngan'gityemerri - Reid p.c.)

(95) ngi-rim-fif

ngi-rribem-6fi

ngi-bem-fif

I SGS-sit.PR-smoke

ISGS-stand.PR-smoke

I SOS-lie.PR-smoke

'I am sitting smoking.'

'I am standing smoking.'

'I am lying smoking.'

(Reid 2000: 338)

For an example of associated motion with a transitive predicate, we may consider the following from Gurr-goni (Green, 1995: 283).
(96) njirr-rre+rrmi-rri
njiwurr-ma-nay
gut-djardi wane
3MIN:A.IAUG.O-pound + REDUP-PRE
IAUG.S-go.along-PRE
IV-rain
big
'We went along being pelted by heavy rain.'
[lit. 'Big rain pounded us while we went.']

This example is also of interest because the first person entity would in most theories bear different thematic relations to the two predicates - the theme/patient of 'pound' and the agent of 'go'. In some theories, it might be classified as the theme of 'go', thereby giving it the same thematic relation to both predicates. However, there are examples of serial verb constructions where a single entity bears distinct roles under any theory of thematic relations.

$\begin{array}{lllll}\text { wó } & \text { qiú } & \text { tã } & \text { dàibiăo } & \text { wǒ } \\ \text { ISG } & \text { beg } & \text { 3SG } & \text { represent } & \text { ISG }\end{array}$

'I begged him/her to represent me.' (Mandarin Chinese - $\mathrm{Li}$ and Thompson, 1981: 607)

(98) wón mu oti yó
they drank wine drunk
'They drank wine until drunk.' (Yoruba - Bamgbose, 1974: 24)

In merger constructions, an entity can bear only one thematic role within the overall complex predicate. ${ }^{7}$

"We omit from consideration here reflexive and reciprocal constructions. 
Both merger and coindexation constructions allow the formation of 'light verbs'. However, the process of light verb formation is quite distinct in each construction type. As we have seen, one common pattern in serial verb constructions is that the 'take' verb adds an instrumental argument to the clause:

(99) fu burede ije sime abe ufu he bread DEF knife take cut

'He cut the bread with the knife.' (Barai - Foley and Olson, 1985: 44)

The LCS of the 'take' verb is shown in (100).

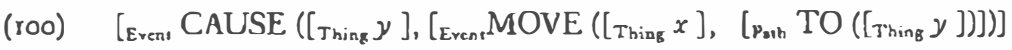

An implicature of this LCS is that entity $y$ has possession of entity $x$. It is a development of this implicature which survives in the serial verb construction ( $y$ has the knife and $y$ cuts the bread $\rightarrow y$ cuts the bread with the knife). This is an example of what is commonly analysed as 'grammaticalisation'.

By contrast, in merger constructions light verbs are created by deleting inner conceptual structure from the LCS of finite verbs.

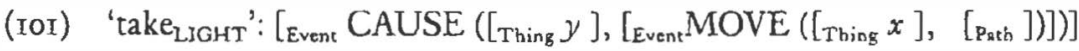

This allows the merger to add additional material into the open inner positions of the argument structure. The coverb rang 'hit' has the following LCS.

(102) [Event $\operatorname{CAUSE}\left(\left[\left[_{\text {Thing }} \gamma\right]\right.\right.$, [Even MOVE $\left(\left[\right.\right.$ Thing $\left._{\text {The }} x\right],\left[{ }_{\text {Path }}\right.$ TO $\left.\left.\left.\left(\left[_{\text {Thing }} z\right]\right)\right]\right)\right]$

This coverb may successfully unite with the light verb to form a standard transitive predicate, as in (103).

$$
\begin{aligned}
& \text { rang }=\text { ng-anyi } \quad \text { Ø-manuga } \\
& \text { hit }=\text { I SG.S/3SG.O-TAKE.PC } \quad \text { MA-rock } \\
& \text { 'I hit a rock.' (Not: 'I hit it with a rock.') (Marra - Heath 198r) }
\end{aligned}
$$

In order to express an instrumental use, Marra requires an oblique noun class prefix, one of whose functions is to mark instrumental case, as in (I04).

$$
\begin{array}{ll}
\text { rang=nga-nyi } & \text { na-manuga } \\
\text { hit=ISG.S/3SG.O-TAKE.PC } & \text { MA.OBL-rock }
\end{array}
$$

'I hit it with a rock.'

Instrumentals cannot be expressed with verbs in Marra, nor in any other coverb language that we are aware of. 
The same kind of opposition is found with the 'give' verb. In serialising languages commonly the 'give' verb adds a Benefactive argument to the clause (Twi - Lord 1993: 32):

a. agenkwã no wú mãã yẹn
Saviour the die 'give us
'The Saviour died for us.'

We propose that, in this case, what survives in the grammaticalised version of 'give' is the thematic relation of Benefactive. In Jackendoff's (I990) model, thematic roles depend upon the 'action tier'.

By contrast, the presence of the 'give' verb in a merger construction does not encode non-subcategorised Benefactive type relations. We may consider the previously discussed Ngaliwurru example (80), repcated here as (ro6) for convenience.

$\begin{array}{ll}\text { (ro6) darnku } & \text { gani-ngarna-ny } \\ \text { full } & \text { 3SGS.3SGO-give-PP }\end{array}$

'She gave him (food) and he become full.' ('She fed him./She gave him a feed.') (Not: 'She became full for/on him.')

As indicated, this does not describe an action performed affecting someone else. As elsewhere, this does not follow from real-world considerations. A malefactive interpretation - 's/he became full negatively affecting him' at least is plausible.

\subsection{Correlations between conceptual oppositions and morphosyntactic oppositions}

In our presentation of materials thus far, the semantic opposition between merger and coindexation has generally matched the categorial opposition between coverb constructions and serial verb constructions. Coverb constructions involve the merger of conceptual structures, whereas serial verb constructions involve coindexation.

While coverb constructions most commonly map to merger structures, they do not necessarily do so. Thus, $\mathrm{Ngan}$ 'gityemerri is a language which on initial inspection appears to class structurally with the other Australian languages so far discussed - Jaminjung, Marra, Wagiman. It has a large open class of coverbs and a small closed class of finite verbs. Most verbal clauses involve a coverb construction. However, there are a number of differences between Ngan'gityemerri on the one hand, and other Australian languages on the other hand. 
First, as we have seen, coverb constructions in Ngan'gityemerri can convey meanings, such as associated motion (94) and stance (95), which coverb constructions cannot generally in Australian languages. Examples (94) and (95) are repeated here as (107) and (108) for convenience.

$\begin{array}{llll}\text { (I07) } & \text { nga-ganim-fifi } & & \\ & \text { ISGS-go.PR-smoke } & \\ & \text { 'I'm going along smoking.' (Ngan'gityemerri - Reid p.c.) } \\ \text { (I08) } & \text { ngi-rim-ffi } & \text { ngi-rribem-fif } & \text { ngi-bem-fif } \\ & \text { 1SGS-sit.PR-smoke } & \text { ISGS-stand.PR-smoke } & \text { iSGS-lie.PR-smoke } \\ & \text { 'I am sitting smoking.' } & \text { 'I am standing smoking.' } & \text { 'I am lying smoking.' }\end{array}$

(Reid, 2000: 338)

Second, the coverb construction in Ngan'gityemerri is syntactically different from that in most other Australian languages. As previously discussed (section 2.2), the configurationality of coverb constructions varies somewhat among Australian languages. In some languages, such as Jaminjung and Wagiman, coverbs have a greater degree of independence. However, even in these languages, in at least 80 percent of occurrences a coverb immediately precedes a finite verb. In other languages such as Marra, the coverb construction is configurational and coverbs necessarily immediately precede a finite verb. In Ngan'gityemerri, as illustrated in (I07) and (I08), the coverb necessarily immediately follows the verb.

Third, the inventory of finite verbs in Ngan'gityemerri is very different from that in most other Australian languages. The inventories of Jaminjung (Schultze-Berndt 2000: 99-102) and Wagiman (Wilson 1999: 24) are set out in (IOg) and (IIO).

(109) Jaminjung

Intransitive: be, be sick, burn, come, do/say, go, fall (7 verbs)

Transitive: approach, be angry with, bite, bring, chop, cook, deceive, eat, excrete, fear, follow, get, give, have, hear, hit, leave, make, put, remove, see, 'sing' someone, spear, step on, swear at, take, throw (27 verbs)

(IIo) Wagiman

Intransitive: be (2 distinct verb roots - historically 'lie' and 'sit'), be afraid, be egocentric/narcissistic, become, burn, come, cry, do/ say, dream, fall, go, stand, stay (14 verbs)

Transitive: beget/name, bite, bring, cause, chase, cook, cut, deceive, eat, follow, fuck, get, give, have/keep, hear, hit, leave, look for, loose, make, put, see, sew, 'sing' someone, spear, step on, take, tell off, throw (29 verbs) 
These inventories are very similar. There is a comparatively small number of intransitive verbs. The stance verbs are notable by their absence. ${ }^{18}$ There are a large number of transitives. These Australian inventories may be compared with the inventory of light verbs appearing in Persian coverb constructions (Folli et al. 2005: 1370)、

(III) Persian (abouc I6o directly inflecting verbs - I5 appear commonly as light verbs)

Intransitive: be, become, come, fall, go (5 verbs)

Transitive: arrange, bring, carry, catch/take, collide, do/make, entrust, give, have, hit, pass/cross, pull, scatter, show, throw, tie, wash ( 17 verbs)

This Persian inventory is similar to the two Australian inventories. The Ngan'gityemerri inventory is set out in Table 2.I.

There are two obvious differences between the Ngan'gityemerri inventory and the usual inventory, as illustsated in (I09-1II). First, four of the seven members of the Ngan'gityemerri intransitive inventory are stance verbs - lie, perch, sit, stand. Second, Ngan'gityemerri has a set of formally distinctive reflexive (detransitive) directly inflecting verbs.

$\begin{array}{ll}\text { nge-riny-Ø-syirr } & \text { nge-meny-syirr } \\ \text { ISGA-HANDS-3SGO-scratch } & \text { IsgS-HANDS.REFL-scratch } \\ \text { 'I scratched her.' } & \text { 'I scratched myself.' }\end{array}$

(Reid 2000: 348)

It may be observed that these detransitive verbs bear no formal relationship to their corresponding transitives. Specifically, detransitive verbs of this kind are not part of the inventory of directly inflecting and/or light verbs in most languages with coverb constructions.

In this respect, the inventory of Ngan'gityemerri is more similar to the inventories of classificatory verbs in Athabaskan languages, where pairs of controlled and non-controlled verbs show no formal relationship to one another, as shown in Table 2.2.

It may be noted that some Athabaskan languages have associated motion constructions (Rice: this volume), of a similar kind to those we find in Ngan'gityemerri, as in (107-108).

The differences between Ngan'gityemerri and other languages with the usual coverb patterns are summarised in (I13).

(II3) a. The coverb obligatorily follows the verb, as opposed to normally or obligatorily preceding it.

18 The 'stand' verb in Wagiman is extremely rare. It occurs only with a couple of coverbs and is not obligatory with these. It does not occur independently, unlike all the other finite verbs. 
Table 2.I Ngan'giryemerri finite verb inventory (Reid 20no: 337)

\begin{tabular}{|c|c|}
\hline arrive & involving arrival/emergence \\
\hline go & carried out in motion \\
\hline lie & carried out in a lying posture \\
\hline perch & carried out up off the ground \\
\hline sit & carried out in a sitting posture \\
\hline stand & carried out in a standing posture \\
\hline travel & carried out in motion (goal-oriented motion) \\
\hline \multicolumn{2}{|l|}{ Transitive } \\
\hline do/say & speech and unspecified doing (do things, say things) \\
\hline poke & using long, thin things in point contact (stab, prod) \\
\hline sce & performed with the eyes (look at, watch, keep an eye on) \\
\hline slash & using hinged trajectory and edge-on contact (sweep, slice) \\
\hline take & taking/bringing things \\
\hline bash & using vertical trajectory and lumpy contact (thump, crash) \\
\hline feet & holding things down with the feet (tread on, kick, walk on) \\
\hline hands & holding things within the grasp of the hands (grab, hold, grip) \\
\hline heat & applying heat (burn, melt, warm, light) \\
\hline mouth & holding things within the mouth (chew, suck, some speech verbs) \\
\hline move & moving things to a different place (shift, throw, push) \\
\hline pull & pulling things (pull, tow, lever up) \\
\hline snatch & acquiring things (get, pick up) \\
\hline suck & ingesting things (eat, drink) \\
\hline \multicolumn{2}{|l|}{ Reflexive } \\
\hline bash.refl & reflexive activity using vertical trajectory and lumpy contact \\
\hline do/say.refl & reflexive speech (talk to yourself, mutter under your breath) \\
\hline feet.refl & reflexive activity holding things down with feet \\
\hline hands.refl & reflexive activity holding things within the grasp of the hands \\
\hline heat.refl & reflexive activity by applying heat \\
\hline mouth.refl & reflexive activity holding things within the mouth \\
\hline move.refl.dyn & reflexive activity by moving things to a different place-dynamic \\
\hline move.ref.stat & reflexive activity by moving things to a different place-stative \\
\hline see.rcfl & reflexive activity performed with the eyes \\
\hline
\end{tabular}


Table 2.2 Slave classificatory verbs (Rices989: 789-790)

\begin{tabular}{lll}
\hline \hline action by poking (with stick, hand) & controlled & $\emptyset$-kwi, Ø-ge \\
& non-controlled & $\emptyset$-ka \\
action by hand & controlled & $h$-nih \\
& non-controlled & $\emptyset$-tsi \\
action by foot & controlled & $\emptyset$-Zéh \\
& non-controlled & $\emptyset$-táh \\
\hline
\end{tabular}

b. The stance verbs constitute half of the inventory of intransitive finite verbs, as opposed to being absolutely or effectively absent.

c. The inventory of transitives is matched by an inventory of formally unrelated detransitives, as opposed to detransitivisation being marked by standard morphological or syntactic structures.

d. Meanings such as 'associated motion' and 'associated stance' may be conveyed by the coverb construction in Ngan'gityemerri. These meanings cannot be conveyed by coverb constructions in most languages.

The features listed in (113) are also characteristic of the western and northern neighbours of Ngan'gityemerri - Marranj, Marramaninjsji, Marringarr, Marrithiyel, Matige, Murriny-Patha. This suggests that the features in (1r3) are not a chance collocation, but follow from significant structural differences between the coverb construction in these languages, and the coverb constructions found in the great majority of other languages.

The patterns found in Ngan'gityemerri and its neighbours are not the only types of departures from the usual patterning of the coverb construction. In three Australian languages, Kamu, Malak-Malak, and Matngele, coverbs can combine with other coverbs in serial constructions to form complex predicates through coindexation, as in (ir4).

(II4) dal-ngak-ma=gu-yang

poke-eat-IMPF $=3 S G S-G O: P R$

'(The bird) is pecking (at the food).'

[lit. '(The bird) is poking, eating (the food).'] (Kamu - Harvey feldnotes)

In summary, it is clear that there is no necessary connection between the existence of coverbs as a part-of-speech class, their combination with finite verbs to form coverb constructions, and the event structures which are 
possible within a single clause. In many languages with coverbs, only simplex event structures are possible within a single clause. In a small group of Australian languages from the north-western Northern Territory, however, more complex event structures can be encoded with coverb constructions.

The situation with serial verb constructions is unclear. In terms of the available evidence, it appears that a subset of the serial verb construictions in many languages may map to coindexation conceptual structures. It is conceivable that in some languages with serial verb constructions, only simplex event structures may be possible within a single clause, suggesting that these languages may only allow merger of LCS, and not coindexation, as with many languages with coverb constructions. It is also conceivable that languages with serial verbs may allow merger and coindexation as mapping mechanisms at different levels of syntactico-semantic structure (as in the 'nuclear' vs. 'core' juncture model of Van Valin and LaPolla 1997, for example). These are questions for future research. There are also other morphosyntactic structures such as Germanic particle + verb constructions, whose status with respect to the merger vs. coindexation distinction is likewise an area for further research.

\section{II Conclusion}

We have shown that complex predicates may be divided into two classes in terms of their correspondence with conceptual structure. One class of complex predicates - the merger construction - groups with monomorphemic predicates in that merger constructions only allow predicates which correspond to the classic Vendlerian verb classes. Various authors (e.g. Dowty 1979, Rappaport Hovav and Levin 1998) have proposed that the Vendlerian classes represent a constraint on what kinds of events may be lexicalised as monomorphemic verbs in languages. Merger constructions therefore obey this constraint, and for this reason we have characterised them as realising 'simplex' event structures. The other class - coindexation constructions - groups with multi-clause sequences, in allowing more complex event structures, which cannot in many cases be expressed by simple monomorphemic predicates in other languages. It is not clear whether there are limits on the complexity of event structures expressible by coindexation constructions.

We have also shown that this distinction in conceptual structures is not predictable from the morphosyntactic structure of complex predicates, although there is a clear bias in most languages with coverb constructions towards merger of conceptual structures, rather than coindexation. The deeper question, which we have not addressed here, is why it is that a complex predicate construction such as the coverb constructions of Marra, Wagiman, and Jaminjungan should be so constrained. We have 
similarly not attempted to explain which particular finite verbs become selected for use in coverb constructions. Again, there are relatively clear preferences for verbs with 'generic' meanings such as 'take', 'get', and 'hit' rather than more specific meanings, though there are except ions to this general pattern in most languagges with multiple coverbs, such as Marra janj/i 'tell', or Bardi -ar-'spear lice' (Bowern 2004) (see Amberber, Baker and Harvey 2007). These are topics for future research.

\section{References}

Aikhenvald, A. 2006. Serial Verb Constructions in Typological Perspective. In Serial Verb Constructions: A Cross-Linguistic Typology, Alexandra Aikhenvald and R. M. W. Dixon (eds), I-68. Oxford: Oxford University Press.

Amberber, M. 2002. Verb Classes and Transitivity in Amharic [Lincom Studies in Afro-Asiatic Linguistics o6]. Muenchen: Lincom Europa.

Amberber, M., Baker, B., and Harvey, M. 2007. Complex Predication and the Coverb Construction. In Language Description, History and Development: Linguistic Indulgence in Memory of Terry Crowoley. Jeff Siegel, John Lynch, and Diana Eades (eds), 209-19. Amsterdam: John Benjamins.

Bamgbose, A. 1974. On Serial Verbs and Verbal Status. Fournal of West African Linguistics 9:17-48.

Bodomo, A. B. 1997. Paths and Pathfinders: Exploring the Syntax and Semantics of Complex Verbal Predicates in Dagaare and Other Languages. PhD dissertation, Trondheim: The Norwegian University of Science and Technology.

Bowern, C. 2004. Bardi Verb Morphology in Historical Perspective. PhD dissertation, Harvard.

Bruce, L. 1979. The Alamblak Language of Papua Nem Guinea (East Sepik). Canberra: Pacific Linguistics Series C: 8r.

Butt, M., this volume. The Light Verb Jungle: Still Hacking Away.

Crowley, T. 1987. Serial Verbs in Paamese. Studies in Language 11:35-84.

2002. Serial Verbs in Oceanic: A Descriptive Typology. Oxford: Oxford University Press.

Dowty, D. R. 1979. Word Meaning and Montague Grammar: The Semantics of Verbs and Times in Generative Semantics and Montague's PTQ. Dordrecht: Reidel.

Foley, W. A. 1986. The Papuan Languages of Nes Guinea. Cambridge: Cambridge University Press.

Foley, W. A. and Olson, M. 1985. Clausehood and Verb Serialisation. In Grammar Inside and Outside the Clause, Johanna Nichols and Anthony C. Woodbury (eds), 17-60. Cambridgc: Cambridge University Press.

Foley, W. A. and Van Valin, R. D. 1984. Functional Syntax and Universal Grammar. Cambridge: Cambridge University Press.

Folli, R., Harley, H., and Karimi, S. 2005. Determinants of Event Type in Persian Complex Predicates. Lingua II5: 1365-40r.

Green, R. 1995. A Grammar of Gurr-goni: A Language of North Central Arnhem Land. PhD dissertation, Canberra: ANU. 
Gruber, J. I965. Studies in Lexical Relations. PhD dissertation, MIT. [Published as part of Lexical Structures in Syntox and Semantics: Amsterdam: NorthHolland, r976.]

Hale, K. and Keyser, S.J. 1993. On Argument Structure and the Lexical Expression of S'ntactic Relations. In The Viem from Building 20: Essays in Linguistics in Honor of Sylvain Bromberger, Kenneth Hale and Samuel Jay Keyser (eds), 53-109. Cambridge, MA: MIT Press.

2002. Prolegomenon to a Theory of Argument Structure. Cambridge, MA: MIT Press.

Heath, J. 1981. Basic Materials in Mara: Grammar, Texts and Dictionary. Canberra: Pacific Linguistics 6o: Series C: 60.

Jackendoff, R. 1983. Semantics and Cognition. Cambridge, MIA: MIT Press.

I990. Semantic structures. Cambridge, MA: MIT Press.

I991. Parts and Boundaries. Cognition 4r: 9-45.

1996. The Proper Treatment of Measuring Out, Telicity, and Possibly Even

Quantification in English. Natural Language and Linguistic Theory 14, 2: $305-54$.

1997. The Architecture of the Language Faculty. Cambridge, MA: MIT Press.

2002. Foundations of Language: Brain, Meaning, Grammar, Evolution. Oxford:

Oxford University Press.

Levin, B. and Rappaport Hovav, M. 2005. Argument Realization. Cambridge: Cambridge University Press.

Li, C. and Thompson, S. Ig81. Mandarin Chinese: A Functional Reference Grammar. Berkeley: University of California Press.

Lord, C. 1993. Historical Change in Serial Verb Constructions [Typological Studies in Language, vol. 26]. Amsterdam/Philadelphia: John Benjamins.

Matthews, S. and Yip, V. 1994. Cansonese: A Comprehensive Grammar. London/ New York: Routledge.

Megerdoomian, K. 2001. Event Structure and Complex Predicates in Persian. Canadian Journal of Linguistics 46(I/2): 97-r25. Special Issue on the Syntax of Iranian Languages.

Ramchand, G. and Svenonius, P. 2002. The Lexical Syntax and Lexical Semantics of the Verb-Particle Construction. In WCCFL 21 Proceedings, L. Mikkelsen and C. Potts (eds), 387-400. Somerville, MA: Cascadilla Press.

Rappaport Hovav, M. and Levin, B. 1998. Building Verb Meanings. In The projection of arguments, Miriam Butt and Wilhelm Geuder (eds), 97-134. Stanford, CA: CSLI

Reid, N. 2000. Complex Verb Collocations in Ngan'gityemerri: A Non-derivational Strategy for Encoding Valency Alcernations. In Changing Valency: Case Studies in Transitivity, R. M. W. Dixon and Alexandra Aikhenvald (eds), 333-59. Cambridge: Cambridge University Press.

Rice, K. 1989. A Grammar of Slave. Berlin and New York: Mouton de Gruyter.

This volume. Activity Incorporates in Some Athabaskan Languages.

Schultze-Berndt, E. 2000. Simple and Complex Verbs in Jaminjung. Nijmegen: Catholic University.

Sebba, M. 1987. The Syntax of Serial Verbs: An Investigation into Serials in Sranan and Other Languages. Amsterdam: John Benjamins. 
Van Valin, R. D. r993. A Synopsis of Role and Reference Grammar. In Advances in Role and Reference Grammar, Robert D. Van Valin, Jr. (ed.), I-I64. Amsterdam: John Benjamins.

Van Valin, R. D. and LaPolla, R.J. 1997. Sj/ntax: Structure, Meaning and Function. Cambridge: Cambridge University Press.

Vendler, Z. 1967. Linguistics in Philosophy: Irhaca, NY: Cornell University Press.

Wilson, S. 1999. Coverbs and Complex Predicates in Wagiman. Stanford, CA: CSII. 


\section{University Library}

\section{- M M I N E R VA A gateway to Melbourne's research publications}

Minerva Access is the Institutional Repository of The University of Melbourne

Author/s:

Baker, B

Title:

Complex predicate formation

Date:

2010-01-01

Citation:

Baker, B. (2010). Complex predicate formation. Amberber, M (Ed.). Baker, B (Ed.). Harvey, M (Ed.). Complex Predicates: Cross-Linguistic Perspectives on Event Structure, (1), pp.13-47. Cambridge University Press.

Persistent Link:

http://hdl.handle.net/11343/31185 